\title{
Da negação aos direitos à vulnerabilidade: 0 caso das domésticas paraguaias inseridas em Foz do Iguaçu (BR)
}

\author{
Eduardo Alves Gomes ${ }^{1}$ \\ Silvia Lima de Aquino ${ }^{2}$
}

\section{Resumo}

Este artigo busca refletir sobre as condições de trabalho de um grupo de empregadas domésticas paraguaias inseridas em Foz do Iguaçu (BR), de modo a evidenciar a situação de fragilidade que elas são expostas diariamente. Para tanto, o artigo se subsidiará nas percepções das próprias empregadas domésticas acerca de seu trabalho cotidiano. Tais percepções foram coletadas a partir da realização de um trabalho de campo, com a aplicação de entrevistas semiestruturadas a 8 domésticas paraguaias entre o mês de fevereiro de 2019.

Palavras-chave

Vulnerabilidade; Fronteira; Empregada doméstica.

From denial of rights to vulnerability for being foreign: The case of Paraguayan domestic workers in Foz do Iguaçu BR

\begin{abstract}
This article seeks to reflect on the working conditions of a group of Paraguayan domestic workers in Foz do Iguaçu (BR), in order to highlight the fragile situation they are exposed to daily. To this end, the article will be based on the perceptions of the maids themselves about their daily work. Such perceptions were collected from the realization of fieldwork, with the application of semi-structured interviews to 8 Paraguayan domestic workers between February 2019.
\end{abstract}

\section{Keywords}

Maid; Border; Vulnerability.

Artigo recebido em junho 2020

Artigo aprovado em agosto de 2020 


\section{Introdução}

Foz do Iguaçu é um município Brasileiro, com aproximadamente 260 mil habitantes (IBGE Cidades) localizado na região Oeste do Estado do Paraná. Faz divisa com o Paraguai e com a Argentina, e é famosa por dois atrativos turísticos, sendo eles, as Cataratas do Iguaçu, uma das sétimas maravilhas do mundo, que coloca o turismo ecológico como um dos propulsores da economia local e a Usina Hidrelétrica de Itaipu que, além de auxiliar no turismo por sua engenhosidade, produz energia que abastece parte do Brasil e Paraguai.

Cidades fronteiriça como essa, possuem singularidade e dinamismo “(...) pois se faz pela territorialização de grupos humanos e de redes de circulação e intercâmbio, unidos pela permeabilidade dos limites estatais através da comunicação entre populações pertencentes a diferentes sistemas de poder territorial" (MACHADO, 2006, p. 61). Assim, esse espaço é marcado por troca e comunicação e, ao mesmo tempo, por tensão e conflito (MACHADO, 2006).

Situações muito particulares são visualizadas em áreas de fronteira. O habitante dessas cidades, por exemplo, “(...) muitas vezes mora em um país e trabalha no outro, compra na cidade vizinha por um preço mais barato ou ainda busca serviços de saúde, educação e outros benefícios sociais do outro lado da fronteira, conforme a disponibilidade, acesso, preço ou qualidade desses serviços" (CARDIN e ALBUQUERQUE, 2018, p. 120).

A mobilidade dos trabalhadores para além de "suas divisas" é algo corriqueiro e a motivação acontece principalmente pela falta de emprego. A busca por melhores condições de vida leva brasileiros até o lado paraguaio para trabalharem em lojas, supermercados, táxis, mototáxis (LOZANO, 2017) e em atividades ligadas ao contrabando de mercadorias vindas do Paraguai e distribuídas no Brasil (CARDIN, 2011). Pelo mesmo motivo, os (as) paraguaios(as) se deslocam para o lado brasileiro para trabalharem como empregadas domésticas, pedreiros, ambulantes, lavadores de carros, garçonetes e vendedores (FARINA, 2015). 
Dentre os trabalhos que paraguaios(as) desenvolvem em Foz do Iguaçu, o serviço doméstico é o que mais chama atenção devido à quantidade de estrangeiras que se vinculam nesta atividade. Esse assunto inclusive já foi objeto de pauta na imprensa nacional. Em 2011, o site G1. Clobo 3 por exemplo, publicou uma reportagem com o título "Paraguaias cruzam a fronteira para trabalhar ilegalmente no Brasil” (G1 GLOBO, 2011). Notícia parecida foi realizada pelo jornal Gazeta do Povo com o título "Paraguaios cruzam fronteira para trabalhar ilegalmente em Foz" e subtítulo “domésticas, babás e trabaIhadores da construção civil buscam salários maiores que os pagos no Paraguai" (GAZETA DO POVO, 2011) ${ }^{4}$

Tendo como ponto de partida a circulação de trabalhadores entre a fronteira de Foz do Iguaçu (BR) x Ciudad del Este (PY), e visando aprofundar um estudo em relação a essa categoria de trabalhadoras, este artigo busca refletir sobre as condições laborais de um grupo de empregadas domésticas paraguaias inseridas neste município e expor algumas situações vivenciadas por elas, em seus respectivos locais de trabalho, para demonstrar um pouco dos dilemas e das dificuldades enfrentadas no labor. Tais percepções foram coletadas a partir da aplicação de entrevistas semiestruturadas junto a um grupo composto por estas trabalhadoras.

Dito isso, o presente trabalho está dividido em 5 partes, além da introdução e conclusão. Na primeira parte realiza-se uma breve reflexão sobre os conceitos de imigrante e mobilidade fronteiriça. Em seguida apresenta-se a metodologia utilizada para a coleta de dados. Na terceira, buscou-se compreender a percepção das trabalhadoras sobre os motivos que levam os empregadores locais a contratarem seus serviços. Na quarta parte, realiza-se uma discussão acerca das condições laborais das empregadas domésticas entrevistadas. E por último, abriu-se um espaço para que as trabalhadoras pudessem relatar situações vivenciadas nas casas dos empregadores que marcaram suas vidas. 


\section{Migração, mobilidade fronteiriça e trabalho doméstico em Foz do Iguaçu - PR}

Nesse contexto fronteiriço, em especial, entre a fronteira Foz x Ciudad del Leste, pode-se visualizar a existência de trabalhadores que se movimentam entre os países, tendo por objetivo a venda de sua força de trabalho. Sobre isso, Cardin (2011, p. 41) esclarece que "as diferenças econômicas e políticas existentes na fronteira garantem a ocorrência de inúmeras formas de trabalho sustentadas basicamente pelas desigualdades existentes entre os países limítrofes".

É interessante pensar o cotidiano desses trabalhadores a partir dos fenômenos migratórios, pois assim se compreende as particularidades da fronteira também nesse aspecto. Em um artigo intitulado "Notas para o estudo dos processos migratórios no Brasil", o pesquisador Eric Gustavo Cardin discute brevemente alguns pontos sobre a migração que são importantes para se contextualizar o processo migratório em área de fronteira. Para o pesquisador, "o fenômeno da migração diz respeito ao movimento de pessoas, grupos, comunidades ou povos de um lugar para outro" (CARDIN, 2012, p.02). Quando as pessoas mudam de localidade (região/país) não tendo uma previsão de retorno ou com uma previsão distante, em termos conceituais, esse deslocamento é chamado de migração permanente. Nesse tipo de migração, encontram-se dois conceitos, a "emigração" e "imigração".

Desse modo, o termo emigração refere-se à saída de uma pessoa ou grupo de pessoas de seu ponto de origem em direção a outro. Já o termo imigração tem o sentido contrário, ou seja, significa a entrada do indivíduo no país estrangeiro ou em outra região. Além dessa forma de migração, também existem as migrações temporárias, que podem ser divididas em dois grupos: migração sazonal, “neste tipo de migração, o sujeito sai do seu local de origem em um determinado período do ano e retorna posteriormente, em outro período" (CARDIN, 2012, p.10); e a migração diária ou pendular, "basicamente, este processo diz respeito ao deslocamento diário de trabalhadores de 
uma região de origem ou de residência para outra, com a finalidade de trabalhar, de estudar ou de fazer tratamento médico, com o retorno previsto para o mesmo dia" (CARDIN, 2012, p.10).

A migração diária ou pendular se subdivide em dois casos típicos, um deles se refere a uma parcela da população que é moradora de cidades periféricas, mas que se desloca para trabalhar ou estudar em cidades centrais, na metrópole, criando as chamadas cidades dormitórios. O outro tipo de migração pendular ou diária é também conhecido por commuting ou deslocamento fronteiriço. Nele, ocorre uma movimentação de pessoas de um país para o outro (CARDIN, 2012). Tal fenômeno é recorrente em cidades que fazem fronteira internacional, sendo este o caso de Foz do Iguaçu-PR. Nessa situação, a pessoa se desloca para trabalhar ou estudar de um país para o outro e retorna diariamente ou com certa regularidade para sua residência. Alguns autores preferem utilizar para esses casos o termo "mobilidade fronteiriça" ou "mobilidade pendular transfronteiriça".

A mobilidade é compreendida como um ato de sair de um local e se deslocar para outro, por tempo determinado ou não e o trabalhador pendular é entendido como aquele que faz o movimento de ir e vir de um local para outro. O transfronteiriço é acrescentado nessa definição, porque atravessa uma fronteira entre países, configurando-se a "mobilidade pendular transfronteiriça” (LOZANO, 2017, p. 29).

É necessário perceber que migração fronteiriça e mobilidade fronteiriça são conceitos que explicam fenômenos diferentes, embora coexistentes. No primeiro caso, a fixação de residência é uma espécie de migração limítrofe; no segundo, trata-se de um dos tipos de migração pendular, ocorrida em região de fronteira internacional (LIMA e CARDIN, 2016).

A partir do exposto, é possível perceber que, em cidade com fronteiras internacionais, como o caso deste estudo, nem sempre um trabalhador estrangeiro poderá ser considerado um imigrante, isso por- 
que, nestas regiões, é comum o trabalhador se direcionar para o outro país, desenvolver suas atividades laborais e retornar diariamente para seu local de origem. Nesse sentido, essas "idas e vindas" enquadram-se como uma mobilidade pendular fronteiriça.

Todavia, isso não quer dizer que todos os trabalhadores estrangeiros de região de fronteira se utilizem dessa mobilidade. A migração de fato também acontece e isso ocorre quando o estrangeiro fixa residência do outro lado de sua fronteira. Essas duas situações marcam o cotidiano das domésticas paraguaias que laboram na cidade Iguaçuense. Após diálogo com elas, constatou-se que existem entre as entrevistadas as duas situações, ou seja, as imigrantes - que alteraram suas residências para o outro país - e as trabalhadoras que fazem uso da mobilidade.

\section{Metodologia}

O artigo procura refletir sobre as condições de trabalho de um grupo de empregadas domésticas paraguaias inseridas no município de Foz do Iguaçu. Para tanto, apoia-se nas percepções das próprias empregadas domésticas acerca do seu trabalho. Para coletar tais percepções optou-se pela aplicação de entrevista de tipo semiestruturada. Segundo Lakatos e Marconi (2008, p. 278), a entrevista é "uma conversação efetuada face a face, de maneira metódica, que pode proporcionar resultados satisfatórios e informações necessárias" e tem como objetivo compreender as perspectivas e vivências dos participantes. Boni e Quaresma (2005, p. 75) explicam que esse tipo de entrevista "combina perguntas abertas e fechadas, onde o informante tem a possibilidade de discorrer sobre o tema proposto. Ao aplicar entrevistas semiestruturadas o pesquisador deve seguir um conjunto de questões previamente definidas, mas ele o faz em um contexto muito semelhante ao de uma conversa informal".

Para construção deste trabalho, no mês de fevereiro de 2019, foram aplicadas 08 (oito) entrevistas semiestruturadas com mulheres para- 
guaias que trabalham ou trabalharam como empregadas domésticas em Foz do Iguaçu. As entrevistas foram gravadas e, posteriormente, transcritas e analisadas. Antes de iniciar cada entrevista, com o gravador ligado, cada entrevistada autorizou a sua realização e a sua gravação, conforme indica a Resolução $n^{\circ} 510$, de 07 de abril de 2016, sobre a ética em pesquisa nas ciências humanas ${ }^{5}$. As entrevistadas foram Tereza, 16 anos; Francisca, 17 anos; Letícia, 29 anos; Soraya, 31 anos; Cármen, 33 anos; Conceição, 35 anos; Guadalupe, 41 anos; e Maria Flores, 49 anos. Para manter a privacidade das entrevistadas, na análise do material coletado optou-se pela utilização de nomes fictícios para denominá-las. Cabe ressaltar que, transcrições dos depoimentos coletados sofreram adequação ortográfica e gramatical, já que as paraguaias pronunciavam uma espécie de "portunhol", idioma que mistura o português e o espanhol, comumente utilizado nessa fronteira. Todavia, não houve interferência no sentido de modificá-las.

Muitas pessoas em Foz do Iguaçu conhecem domésticas paraguaias ou conhecem outras pessoas que mantém contato com essas trabalhadoras, e esse foi um ponto positivo para o pesquisador, que não teve dificuldades para entrar em contato com a primeira doméstica a ser entrevistada. Inicialmente o pesquisador entrou em contato com algumas pessoas ligadas ao seu ambiente de trabalho para saber se elas mantinham vínculo ou se conheciam pessoas que mantinham vínculos com essas domésticas. Desse primeiro contato, surgiram algumas entrevistas e outras indicações que, posteriormente, renderam novas entrevistas.

\section{A percepção das empregadas domésticas paraguaias sobre os motivos que levam empregadores de Foz do Iguaçu a utilizarem sua força de trabalho}

Antes de adentrar propriamente na discussão principal, é interessante investigar qual a percepção dessas trabalhadoras em relação a preferência de alguns empregadores por seus serviços, para tanto foi 
questionado: Em Foz do Iguaçu, várias famílias contratam domésticas paraguaias. Em sua opinião, por que isso acontece?

Eu acho que é por questão de salário. (GUADALUPE, fev., 2019).

As brasileiras pedem que a carteira de trabalho seja assinada, daí eles pegam as paraguaias, porque as paraguaias não vai ter uma carteira de trabalho para assinar. Eu acho que é por isso. (TEREZA, fev., 2019).

Em primeiro lugar, é porque as paraguaias que trabalha por muito tempo sai de boa, não briga na justiça. E, em segundo, é que não dão problemas e outro é que são responsáveis. (LETíCIA, fev., 2019)

Uma vez eu perguntei para minha patroa, já faz tempo, porque eles gostam mais de paraguaia, ela me falou que gostava porque não tinha compromisso de fazer carteira assinada, ela me falou! Ela falou que não vai pagar $13^{\circ}$ e não tinha férias, daí eu me dei conta que, para a paraguaia, ela não ia dar, né, daí fui me acostumando a trabalhar assim. Ela falou que era obrigatório assinar carteira de brasileira, pagar $13^{\circ}$ e férias, mas acho que ela queria me dizer que paraguaia não tinha direito de receber. (CONCEIÇÃO, fev., 2019).

Partindo das respostas obtidas, percebe-se que as entrevistadas acreditam que o fato de receberem menores salários, não requererem direitos trabalhistas ou, como disse a Letícia, "sair de boa, sem entrar na justiça" são os principais motivos de suas contratações. A negativa dos direitos trabalhistas por parte dos empregadores e a aceitação dessas condições por parte das empregadas, as tornam "atraentes" do ponto de vista econômico. Das oito entrevistadas, nenhuma delas possuía a carteira de trabalho assinada. O registro trabalhista, na realidade, não faz parte do cotidiano desse grupo, apenas uma das entrevistadas possui uma carteira de trabalho, contudo, sem estar com registro. "Eu tenho a carteira, mas até agora a patroa não quer assinar para mim. Nunca conheci uma paraguaia com carteira assinada e eu conheço bastante gente (...)" (LETÍCIA, fev., 2019). 
Letícia explicou que, depois de algum tempo, conseguiu fazer seus documentos no Brasil, incluindo a carteira de trabalho, tendo em vista que ela e sua família residem em Foz do Iguaçu. Notou-se no decorrer dos diálogos com as empregadas paraguaias, que as imigrantes, como é o caso de Tereza, Cármen e Letícia, sentem maior necessidade de ter a documentação brasileira e esse fato pode ter ligação com questões corriqueiras do dia a dia, como precisar se consultar em um posto de saúde ou matricular o filho em uma escola brasileira, por isso, a preocupação em estar com a documentação em dia é maior. Já as demais trabalhadoras domésticas desse grupo entrevistado, ou seja, aquelas que vem trabalhar no Brasil e retornam para o Paraguai, não apresentaram tal preocupação.

A impressão que se tem, analisando o caso desse grupo de trabaIhadoras, é que a regra entre os empregadores do lado brasileiro é não registrar a carteira trabalhista das paraguaias para não arcar com os encargos relativos a esta contratação. Por outro lado, abdicar desses direitos é condição fundamental para as paraguaias conseguirem trabalho no lado brasileiro. Nesse contexto de desigualdades, não faz sentido para elas fazerem qualquer tipo de documentação no Brasil. Muitas sequer sabem da importância em fazê-lo. A circulação de trabalhadores de ambos os lados é comum nessa fronteira e atravessá- la, trabalhar sem direitos e voltar ao seu país no final da tarde é algo já naturalizado, inclusive para elas, que vem de um país onde as condições trabalhistas para empregadas domésticas são péssimas.

\section{Dos direitos trabalhistas e das condições de trabalho}

Férias, $1 / 3$ de férias, $13^{\circ}$ salário, salário-família, licença maternidade são garantias distantes da realidade das entrevistadas. Entre as 8, apenas 2 entrevistadas afirmaram receber dos empregadores $13^{\circ}$ salários e férias. Contudo, esses empregadores que pagam esses "benefícios" são exceções e esse recebimento é pautado por acordos informais, são frutos da "boa vontade" de cada empregador, como se observa nos diálogos abaixo. 
A diferença entre trabalhar com carteira assinada é que você tem uma folga por semana, férias e se você não quiser tirar férias, você recebe. Outra diferença seria o décimo terceiro. Como não trabalho de carteira assinada, é só o salário e mais nada. (CÁRMEN, fev., 2019).

Eu tiro férias, todo mundo tem direito de ter alguns dias de descanso. No final de ano, eu tiro uns 15 dias e vou na minha mãe. Para viajar, eu preciso economizar, porque, quando estou de férias, eu não recebo (risos) e diarista não tem $13^{\circ}$ salário, não tem nada, se não trabalha, não ganha, ganha bem, mas... (GUADALUPE, fev., 2019).

(...) Aqui eles valorizam mais porque dão $13^{\circ}$ salário, férias, feriados, mas nem todos os patrões me pagavam isso, só com essa última que recebo essas coisas. Ela (patroa) só me deu porque eu me informei em redor, no primeiro mês, eu trabalhava até nos feriados, depois, a patroa que eu faço diária que é tia dela conversou com minha patroa mensal e, a partir daí, eu comecei a receber os outros direitos. Aí, quando chegava dia de feriado, eu não ia mais. (LETÍCIA, fev., 2019).

Estão expostos acima três casos, o de Cármen e Guadalupe que recebem apenas o salário e o de Letícia que, após acordo verbal, conseguiu junto a sua nova empregadora o recebimento de alguns benefícios informalmente. A ausência desses direitos compromete seriamente a vida dessas trabalhadoras, pois, atuando sem registro, estarão totalmente desamparadas da proteção do Estado em casos de demissão ou afastamento por motivos de saúde, por exemplo. Um exemplo disso é o caso de Soraya (fev., 2019) que precisou abandonar seu emprego por conta do nascimento de sua filha e, ao sair, não teve direito a licença maternidade.

Sobre esse assunto, a entrevistada argumenta que: “agora, por exemplo, que estou cuidando do meu bebê, eu me viro para me manter, meu patrão não me ajuda mais, e nem o Estado brasileiro. No último trabalho, eu trabalhei um ano e cinco meses, depois, próximo 
de ganhar o bebê, uns quinze dias antes, eu larguei o meu trabalho". Por lei, Soraya teria direito a quatro meses de licença maternidade e só poderia ser dispensada pelo empregador no caso de rescisão de contrato, após o quinto mês do nascimento do bebê. O registro em carteira asseguraria esses direitos a ela, mas como esse não foi o caso, a mesma precisou voltar a morar com os pais para poder se manter e manter as duas filhas.

Na tabela 1, são apresentadas informações sobre os salários, carga de trabalho diário, tempo de intervalos para o almoço e dias de folgas, obtidas junto às entrevistadas.

Tabela 1 - Condições de trabalho das entrevistadas

\begin{tabular}{|c|c|c|c|c|c|c|}
\hline Nomes & $\begin{array}{c}\text { Casas que } \\
\text { trabalha } \\
\text { semanalmente/ } \\
\text { mensalista ou } \\
\text { diarista }\end{array}$ & $\begin{array}{l}\text { Trabalha } \\
\text { quantos } \\
\text { dias por } \\
\text { semana }\end{array}$ & $\begin{array}{c}\text { Horas por } \\
\text { dia/ Horas } \\
\text { por mês }\end{array}$ & $\begin{array}{c}\text { Tempo de } \\
\text { almoço }\end{array}$ & $\begin{array}{l}\text { Dia de } \\
\text { folga }\end{array}$ & $\begin{array}{c}\text { Salário } \\
\text { mensal/ } \\
\text { diária }\end{array}$ \\
\hline Tereza & 1 mensalista & 5 dias & $\begin{array}{c}8 \text { horas } \\
\text { (40h/mês) }\end{array}$ & 1h a $1: 30 \mathrm{~h}$ & $\begin{array}{l}\text { Quintas e } \\
\text { Domingos }\end{array}$ & $\begin{array}{c}\mathrm{RS} \\
1.000,00 \\
\text { mês }\end{array}$ \\
\hline $\begin{array}{l}\text { Francisca* } \\
\text { (base 2019) }\end{array}$ & $\begin{array}{c}1 \\
\text { Mensalista }\end{array}$ & 6 dias & $\begin{array}{l}4 \text { horas } \\
\text { (24h/mês) }\end{array}$ & $\begin{array}{c}\text { Almoçava } \\
\text { em casa }\end{array}$ & Domingo & $\begin{array}{c}\mathrm{R} \$ 800,00 \\
\text { mês }\end{array}$ \\
\hline Letícia & $\begin{array}{c}2 \\
\text { Mensalista e } \\
\text { diarista }\end{array}$ & 6 dias & $\begin{array}{c}8 \text { horas } \\
\text { (48h/mês) }\end{array}$ & $1 \mathrm{~h}$ & Domingo & $\begin{array}{c}\mathrm{R} \$ 1.200,00 \\
\text { mês } \\
\mathrm{R} \$ 100,00 \\
\text { diária }\end{array}$ \\
\hline $\begin{array}{c}\text { Soraya* } \\
\text { (base 2018) }\end{array}$ & $\begin{array}{c}1 \\
\text { Mensalista }\end{array}$ & 4,5 dias & $\begin{array}{c}5 \text { horas } \\
(22,5 \mathrm{~h} / \mathrm{mês})\end{array}$ & 1h a $1: 30 \mathrm{~h}$ & $\begin{array}{l}\text { Sábado e } \\
\text { Domingo }\end{array}$ & $\begin{array}{c}\mathrm{R} \$ 400,00 \\
\text { mês }\end{array}$ \\
\hline Carmen & $\begin{array}{c}1 \\
\text { Mensalista }\end{array}$ & 6 dias & $\begin{array}{c}8 \text { horas } \\
\text { (48h/mês) }\end{array}$ & 1h a $1: 30 \mathrm{~h}$ & Domingo & $\begin{array}{l}\mathrm{R} \$ 1.200,00 \\
\text { mês }\end{array}$ \\
\hline $\begin{array}{l}\text { Conceição* } \\
\text { (base 2018) }\end{array}$ & Diarista & - & 8 horas & - & - & $\begin{array}{l}\mathrm{RS} 120,00 \\
\text { diária }\end{array}$ \\
\hline Guadalupe & $\begin{array}{c}5 \\
\text { Diarista }\end{array}$ & 6 dias & $\begin{array}{c}7 \text { horas } \\
\text { (42h/mês) }\end{array}$ & 15 a $30 \mathrm{~min}$ & Domingo & $\begin{array}{c}\mathrm{R} \$ 115,00 \\
\text { diária }\end{array}$ \\
\hline $\begin{array}{l}\text { Maria } \\
\text { Flores }\end{array}$ & $\begin{array}{c}2 \\
\text { Diarista }\end{array}$ & 4 dias & $\begin{array}{c}8 \text { horas } \\
\text { (32h/mês) }\end{array}$ & 1h a $1: 30 h$ & $\begin{array}{l}\text { Sábado e } \\
\text { Domingo }\end{array}$ & $\begin{array}{c}\mathrm{R} \$ 115,00 \\
\text { diária }\end{array}$ \\
\hline
\end{tabular}

Fonte: Elaborado pelo autor. * Respostas com base no último emprego. 
Foi questionado quais eram os horários que as entrevistadas iniciavam suas atividades laborais e o horário de término. Tendo por base essa informação, foram calculadas as horas de trabalho/dia. Francisca, Soraya e Conceição não estavam trabalhando em Foz do Iguaçu no período das entrevistas, por isso, as respostas foram baseadas nos últimos empregos, cujas bases são respectivamente: 2019, 2018 e 2018.

Na coluna salário "mensal/diária", são observados os valores que cada doméstica recebe por mês ou por dia de trabalho. Das 8 domésticas, 4 delas trabalham como mensalistas fixas em uma casa; 3 trabalham como diarista em mais de uma casa, onde o valor é cobrado por faxina; e 1 doméstica atua nas duas modalidades (de segunda a sexta-feira em uma residência fixa e no sábado faz diária).

Os valores das diárias pagos a cada doméstica praticamente não sofre variação, $R \$ 100,00$ + o valor do transporte (algo entre $R \$ 15,00$ e $\mathrm{R} \$ 20,00)$. Guadalupe trabalha em 5 casas por semana, mas, em uma das casas, trabalha dois dias, totalizando seis dias semanais. Ela recebe algo em torno de $\mathrm{R} \$ 2.400,00$ ao mês, considerando que não falte nenhum dia; Maria Flores trabalha em duas casas, duas vezes por semana em cada, recebe algo em torno de $\mathrm{R} \$ 1.600,00$. Se comparado os salários recebidos pelas "diaristas" com os das "mensalistas", a remuneração do primeiro grupo é maior.

O maior salário visualizado no grupo das domésticas que trabalham por mês é de $\mathrm{R} \$ 1.200$. Embora o salário das diaristas seja maior, o volume de trabalho acompanha essa diferença. Esse fato fica perceptível na fala de Guadalupe quando diz, (...) "é um serviço que se eu estivesse estudado não ficaria, eu não desejo para ninguém, porque é puxado, ainda mais diarista, porque você tem que fazer tudo o que você não fez durante uma semana, então é muito mais puxado". Na visão de Guadalupe, quando se trabalha como mensalista, é possível planejar as atividades que serão realizadas no decorrer da semana e, por esta razão, de certa forma, o ritmo de trabalho é menos intenso. O contrário acontece com as diaristas 
que são pagas para realizar as faxinas acumuladas da semana em um único dia, exigindo, portanto, mais esforço físico.

Seria interessante se pudesse ser estabelecido um comparativo entre os salários que recebem as diaristas brasileiras e os salários que recebem as diaristas entrevistadas, com a finalidade de saber se existem diferenças salariais entre os dois grupos, contudo, essa análise é difícil, uma vez que há uma falta de parâmetro em relação aos valores cobrados pelas diaristas brasileiras, já que a pesquisa centrou-se nas domésticas paraguaias.

Em compensação, é possível estabelecer uma relação entre o valor recebido pelas domésticas entrevistadas que trabalham por mês, e confrontá-lo com o piso salarial das empregadas domésticas (com carteira assinada) que atuam no Paraná. O piso salarial no Paraná das empregadas domésticas, em 2019, é de R\$1.355,20 (DOMÉSTICA LEGAL, 2019). Tereza, Letícia e Cármem são domésticas que trabalham por mês, a média salarial delas gira em torno de $R \$ 1.133,00$, considerando que, sobre o salário-base das domésticas brasileiras com carteira assinada, é descontado um determinado valor referente ao INSS, logo se chega à conclusão que a variação salarial desses dois grupos não é significativa. Mas essa ligeira análise está considerando apenas o salário, vale lembrar que os demais direitos e garantias estabelecidos por lei às empregadas domésticas não estão sendo considerados, porque as entrevistadas sequer têm acesso. Elas, além de não possuírem as proteções trabalhistas, encontram-se totalmente a mercê dos empregadores.

Em relação às horas de trabalho das entrevistadas, observa-se uma média geral de 7 horas/dia, variando entre 4 e 8 horas. Os dias trabaIhados por semana variam de 4 a 6 e as folgas ocorrem entre sábado e domingo, sendo que, para 4 domésticas, apenas o domingo é retirado para descanso. Em termos de horas de trabalho/dia, as horas de trabalho das entrevistadas não são superiores as horas de trabalho de uma doméstica brasileira, de acordo com o que determina a legislação 
trabalhista que no caso é de 8 horas/dia, 44 horas/mês. Mas, essa análise não deve se estender a totalidade de domésticas paraguaias que laboram em Foz do Iguaçu, porque as empregadas paraguaias que são internas, ou seja, as que dormem nas residências dos empregadores (o que não é o caso das entrevistadas desse grupo), trabalham muito mais horas, como será visto na próxima seção.

\section{Situações vivenciadas nas residências dos empregadores que marcaram a vida destas empregadas domésticas}

No decorrer das entrevistas, foram aparecendo relatos, desabafos e histórias que marcaram a vida dessas mulheres. Por essa razão, optou-se por expor esses casos para mostrar a situação de fragilidade que elas são expostas diariamente. São situações delicadas que envolvem trabalho análogo ao de escravo, tentativas de abusos e situações humilhantes, experiências essas que aconteceram nos próprios locais de trabalho. Os relatos seguem a seguinte ordem nominal: Guadalupe, Letícia, Cármen e Soraya. Essa ordem foi estabelecida de forma a permitir que os assuntos e as análises se interliguem.

\section{Relato de Guadalupe}

A entrevista com Guadalupe ocorreu após a saída do seu trabalho. Inicialmente o encontro estava marcado para às $16 \mathrm{~h}$, todavia, minutos antes, a entrevistada remarca o encontro para 16:30 h, porque não tinha terminado o seu serviço. Ao chegar no local combinado, o entrevistador aguarda. Passado algum tempo, desce uma mulher de um prédio carregando em suas mãos sacolas cheias de lixo, ela as deposita no cesto próximo à rua e aguarda. Ao ver a cena, o entrevistador percebe que se tratava da entrevistada, os dois se encontram e caminham até uma padaria próxima. De início, foi perguntado para Guadalupe quais eram as lembranças que ela guardava do seu primeiro trabalho como doméstica em Foz do Iguaçu. Nesse instante, seus olhos se enchem de lágrimas e ela relata uma experiência vivida com um patrão árabe. 
Comecei a trabalhar com o árabe e tive uma decepção muito grande com árabe. O meu patrão quase me estuprou, aí nunca mais trabalhei com árabe, eu tenho pavor deles. Depois, comecei a trabalhar só com brasileiros. Eu trabalhei 7 meses na família desse árabe. Eu dormia na casa deles, eles tinham uma filha de 7 meses e eu que cuidava da filha e limpava a casa. Mas, em certo dia, minha patroa saiu, a menina dormiu, eu estava lavando os pratos, aí ele chegou por trás... mas eu não sei como eu consegui sair correndo, ele correu atrás de mim e falou para eu não contar nada para a esposa dele. Aí eu chorei, chorei e não entrei mais na casa, esperei a patroa lá fora e conversei com ela. Eu contei a verdade, eu não podia ficar mais ali, como que eu ficaria ali? A esposa dele ficou chateada, né, mas... Ela ficou chateada com o marido, porque ela gostava muito de mim, a gente tinha quase a mesma idade, ela vinte e um e eu dezenove, então a gente se dava muito bem. Ela chorou muito quando eu saí, mas não podia ficar mais. Isso foi uma decepção muito grande para mim com árabes. Mas, mesmo assim, eu não desisti. (...) Neste meu primeiro emprego, eu limpava a casa. Almoço, eu não fazia, porque elas faziam a comida deles. Eu dormia na casa e ia para o Paraguai no sábado ao meio dia, na segunda, voltava cedo. Eu trabalhava muitas horas por dia, porque, quando você é interna, os patrões aproveitam, né, depois da janta tem que limpar tudo e só depois dormir, então era muitas horas. Eu começava a trabalhar às 7 horas e árabes jantam tarde, às vezes meia-noite, sei lá, aí depois eu deitava e dormia e no outro dia acordava 7 horas de novo. Eles aproveitavam muito da gente, pagavam muito pouco para as paraguaias. (GUADALUPE, fev., 2019)

Esse depoimento de Guadalupe servirá para problematizar duas questões. A primeira e mais grave, trata-se da falta de segurança que estas domésticas, sobretudo, as que dormem na casa dos contratantes estão expostas. Por estarem em condição de estrangeiras e dormirem nas casas dos empregadores, a situação é agravada. A entrevistada não entrou em detalhes, mas ficou subentendido que, após a tentativa de abuso as autoridades policiais não foram aciona- 
das, ela apenas deixou de trabalhar com aquela família. O fato de não ter havido denúncia pode ter relação com o não pertencimento da entrevistada ao local ao qual está vinculada e por se sentir desamparada, afinal, ela era estrangeira, sem documentação e pobre. Talvez o medo de se expor a uma autoridade policial, nestas condições, tenha contribuído para não levar o caso adiante.

O segundo ponto se refere a carga horária de trabalho/dia. Quando a tabela 1 foi analisada, as horas máximas de trabalho mencionadas pelas entrevistadas foram de 8 horas/dia. Guadalupe traz à tona a realidade de um grupo de jovens paraguaias até então não debatido: as jovens que dormem nas residências dos empregadores em Foz do Iguaçu, e são obrigadas a trabalhar por períodos maiores. De acordo com o relato de Guadalupe, as horas trabalhadas por jornada chegavam a 16 horas, ou seja, o dobro do tempo visualizado na tabela 1. Apesar de não ter mencionado o valor que recebia por aquela jornada de trabalho, mesmo porque já se passaram anos e o valor provavelmente sofreu alterações, Guadalupe mencionou que alguns patrões árabes se aproveitam delas e "pagavam muito pouco". Após relatar este episódio, a entrevistada relembra outra situação que passou quando trabalhava para uma família de brasileiros.

Um dia minha patroa viajou e, quando ela estava viajando, ela falou: "tem um brinco de cristal ao lado da televisão" daí eu achei um brinco e guardei, quando ela voltou de viagem, ela começou a procurar o brinco, só que tinha mais um colar de pérola, daí ela procurava, procurava e não achava, daí ela começou a gritar comigo, e eu não sabia, mas, na verdade, o marido tinha guardado as joias no cofre, mas ele também não lembrou no momento, aí eu revirei a casa, eu chorava e falava patroa não fui eu... De repente, meu patrão se lembrou de ter guardado as joias no cofre e chamou ela, aí acharam... Ela voltou sem graça e falou "eu achei", na hora, eu falei: "preciso do meu dinheiro para sair daqui". "Eu não merecia isso, eu trabalhei enquanto você estava de viagem, você me conhece", e não fiquei mais, foi 
minha última vez. Foi uma decepção muito grande, porque eu gostava muito dela. (CUADALUPE, fev., 2019)

É interessante pensar as relações estabelecidas entre empregada doméstica e a família ao qual é subordinada, isso porque a empregada tem acesso à intimidade familiar, participa da criação dos filhos, cozinha, escuta problemas pessoais, entre outras questões familiares que, por si só, deveriam gerar certa confiança mútua. Nesse novo acontecimento, Guadalupe é acusada de roubo e fica muito chateada diante de uma acusação infundada de sua patroa, patroa essa que tinha certa consideração. A partir deste constrangimento, Guadalupe conta que não teve mais interesse em continuar naquela casa, por isso, pediu que seus dias fossem pagos e se retirou da residência. Ao que deu a entender, novamente, Guadalupe não procurou as autoridades policiais para prestar queixa contra a empregadora, apesar de ter esse direito, pois acusar uma pessoa sem provas constitui crime.

Embora comum, este tipo de situação, onde o empregador acusa a empregada sem ter provas, é configurado crime e cabe indenização moral. Caso semelhante ao de Guadalupe aconteceu na $1^{\circ}$ vara do trabalho em Cuiabá MT, onde um empregador acusou a doméstica de ter roubado $\mathrm{R} \$ 1.000,00$ e, após a acusação, exigiu revistar sua bolsa. Neste momento, diante de tal acusação, a empregada solicita a presença da polícia para que a revista fosse feita. Após a revista dos policiais, foi encontrado em sua bolsa apenas $\mathrm{R} \$ 5,00$ e, diante da acusação infundada, a doméstica entrou com pedido de indenização por danos morais, ganhou a causa e o empregador foi condenado a pagar indenização de R\$10.000,00 (TRT6, 2018).

\section{Relato de Letícia}

Letícia estava ofegante e suada no momento da entrevista, pois foi de bicicleta para o local de encontro, seu meio de transporte. A entrevistada avisou que, ao término da conversa, precisaria ir trabalhar no centro da cidade. Esse percurso levaria mais ou menos 
uns vinte minutos e, como o horário estava avançado, a conversa foi abreviada. O relato de Letícia, que desperta a atenção, também surgiu a partir de suas lembranças do seu primeiro emprego como doméstica em Foz do Iguaçu.

Nesse serviço, não fiquei nem dois dias, não davam de comer, eles fechavam toda a cozinha, fazia comida para uma semana e essa comida era esquentada de novo e ela mesma (patroa) dava a comida para você. Pegava na mão a margarina e passava e eu não gostava, eu joguei fora e ela viu que eu joguei, aí ela não gostou. Às 19 horas, todas as meninas paraguaias se encontravam no parquinho do prédio e os árabes compravam comida para gente, porque sabiam que a gente não comia a comida deles, mas, quando a gente descia nesse horário, minha patroa fechava toda a cozinha e eu não podia pegar nada, nem uma bala. Trabalhava neste prédio umas 7 paraguaias, mas, tinham muitos patrões que não deixava as empregadas paraguaias descer, porque os árabes não gostam que as paraguaias conversem uma com as outras, para não contar como é as coisas, os árabes têm medo. Essa família de árabes me tratava como escrava, para comer, eu tinha que se sentar no chão, na hora do almoço, as mulheres tinham que sentar no chão e os homens sentavam no sofá e eu tinha que comer na lavandaria e tinha que comer a mesma comida. No primeiro dia, tive que acordar bem cedo com eles batendo na porta, umas 6 horas, eles acordavam cedo, porque faziam as orações deles, quando eu entrava no banheiro também, eles cuidavam do horário, aí às 19 horas a gente descia para descansar um pouco e bem tarde ia dormir. No segundo dia de trabalho, eu desci às 19 horas e fugi, ela não queria dar nada para mim, eu fazia tudo certinho, eu era muito nova, mas já sabia trabalhar, aí eu fugi. Ela não queria me dar o meu sapato para descer e eu fugi sem sapatos mesmo, descalça. Ela desconfiou que eu queria ir embora e me disse que eu podia descer, mas que não levaria os sapatos e que era para eu voltar, daí eu fui na portaria e esperei minha irmã me buscar. Eu saí, porque eles não 
tinham paciência comigo, eu não entendia o que eles falavam, aí ela falava uma coisa e eu fazia outra coisa, daí ela se irritava. Você nunca vai encontrar uma brasileira trabalhando com árabes, porque eles são muito exigentes e só as paraguaias que aguentam ficar quietas. (LETíCIA, fev., 2019)

A história de Letícia é parecida com a anterior e ratifica as condições de trabalhos ofertadas as domésticas paraguaias “internas". Letícia começou a trabalhar com 15 anos de idade para esta família árabe, esse foi seu primeiro emprego. Segundo o que descreveu, no prédio em que trabalhou, moravam muitas famílias árabes e tinham várias paraguaias trabalhando nestes apartamentos. Todos os dias, às 19 horas, algumas paraguaias desciam para se alimentar (tendo em vista que tinham dificuldade em comer as comidas árabes) e conversar entre si. Mas nem todas as domésticas desciam, porque muitos patrões não deixavam. Esse relato apresenta uma situação configurada como crime, pois proibir alguém de exercer sua liberdade individual é cárcere privado.

Nessa família que Letícia trabalhou, era costume que as mulheres fizessem suas refeições sentadas no chão e isso a incomodou muito, mesmo porque o chão que ela se sentava era o da lavanderia, diferentemente das outras mulheres que se sentavam no chão da sala. Letícia não se adaptou a esta família, nem aos seus costumes e nem a sua comida. A entrevistada também detalha outra situação constrangedora que ela e outras domésticas paraguaias eram submetidas “(...) conheci meninas que se sentiam constrangidas quando trabalhavam com árabes, porque todas as vezes que saía da casa tinha que mostrar as bolsas, tinha que tirar tudo da bolsa e mostrar para eles antes de ir para casa no final de semana, isso aconteceu comigo também". O gesto de revistar as bolsas gera humilhação, mas, segundo o Portal de Notícias Doméstica Legal (mai. 2016), “o empregador, exercendo o seu poder diretivo e fiscalizador, pode proceder à revista de seus empregados. Toda revista, no entanto, deve sempre observar a integridade da imagem, honra e intimidade do empregado". Embora 
conste que o empregador tenha prerrogativa para realizar a revista, ela vai na contramão da "confiança" que, teoricamente, o empregador deveria ter com a empregada doméstica. Letícia atualmente mora no lado brasileiro com suas filhas e, em um momento da entrevista, foi questionado se ela utilizava o sistema de saúde brasileiro e se chegou a ter problemas para utilizá-lo.

Uma vez eu fiquei doente porque peguei dengue, foi na semana que entrei de férias, então fiquei minhas férias inteiras em repouso. Nesse período, tive dificuldade para conseguir me tratar, porque eu não tinha documento, isso faz uns 4 anos, eu peguei dengue hemorrágica e fiquei muito mal. A filha de uma patroa precisou entrar em contato com um canal de televisão local para eu poder conseguir ser atendida, eu estava desmaiada no chão e ninguém queria me atender, porque eu não tinha documento e me falaram que dengue não matava. Aí, com ajuda dos brasileiros e com a pressão por elas terem chamado a televisão, eles aceitaram me atender. Depois de muita briga, consegui ser atendida. (LETíCIA, fev., 2019).

A pesquisadora Cinthya de F. O. Strada realizou um estudo de caso em sua dissertação de mestrado com o objetivo de entender a organização do atendimento de saúde aos estrangeiros em Foz do Iguaçu (BR). Após sua pesquisa, foi constatado que a falta de orientação em relação a protocolos específicos e a inexistência de padrões de procedimentos, promovem desencontros de informações, deixando os profissionais da saúde inseguros sobre os passos a serem tomados em casos envolvendo estrangeiros. (STRADA, 2018, p.. 94). A não capacitação dos profissionais de saúde para lidar com esse tipo de atendimento favorece situações como as apresentadas por Letícia e por Cármen, no relato seguinte.

\section{Relato de Cármen}

Esta entrevista foi realizada na chácara que Cármen trabalha e vive com seu companheiro e três filhos. Sua casa fica a poucos metros da 
casa dos empregadores. Ao chegar no local combinado, o entrevistador elogiou o espaço por ser arborizado e ter um lago, nisso, Cármen comentou: Este lugar é um paraíso. O fato de a entrevistada ser comunicativa fez a conversa fluir facilmente. No meio do diálogo, o assunto saúde pública foi abordado e, sobre esse assunto, Cármen declarou ter vivido uma situação humilhante.

Buscamos atendimento aqui no Brasil, meus filhos são atendidos ou nos postos de saúde ou na farmácia normalmente. Um filho só que não recebe tratamento, porque ele não tem documento brasileiro e eu não tenho carteira assinada. Tenho uma filha que, mesmo não sendo brasileira, recebe atendimento, porque ela estuda no Brasil, ela pode consultar e já fez várias consultas. Eu fui humilhada ali no posto de saúde, nesse ano. A escola pediu atestado de vacina para matricular minha filha e, como eu não tinha a carteira de vacina do Brasil, eu levei a do Paraguai. Na escola, me falaram que não teria problema, eu conversei com a professora e a diretora da escola e expliquei minha situação, o pessoal da escola falou que eu poderia ir, porque eles iriam me dar o documento, porque ela já tinha tomado vacina no Brasil, mas não tinha a carteira daqui. No posto de saúde, mandaram eu jogar no lixo a carteira de vacina do Paraguai, então me senti humilhada pela situação. Eles não queriam me dar o documento, mas daí teve uma pessoa, falo que foi um anjo, uma enfermeira sentiu dó de mim e me auxiliou, ela me ajudou mesmo passando por cima das pessoas que não queriam me ajudar e fez uma carteira nova de vacina e assim consegui o documento. Esse dia me senti muito humilhada, falou para mim que eu estava ilegal e tudo, mesmo comprovando que eu tinha filho brasileiro e que moro aqui faz anos. Cheguei a ir duas vezes neste posto, só consegui o documento no terceiro dia. Fiquei na fila à toa, perdi meu tempo, mas que consegui eu consegui. (CÁRMEN, fev., 2019).

Outra vez o despreparo no atendimento conferido aos estrangeiros é visualizado. Não haveria necessidade de a atendente ter mandado Cármen jogar a carteira de vacina de sua filha no lixo. Esse fato, 
mesmo que inconsciente, passa a impressão de que as vacinas tomadas no Paraguai não possuem valor ou que não prestam. Um diálogo com mais respeito e um protocolo de atendimento para usuários estrangeiros, provavelmente, reduziria episódios como esse. Precisou de uma enfermeira se comover diante daquela situação, tomar uma decisão isolada, para que Cármen conseguisse obter a carteira de vacina de sua filha para levar na escola. Como observado por Strada (2018, pg. 94), "se faz urgente a implantação de protocolos e fluxos de trabalho para que haja o atendimento aos usuários estrangeiros de forma adequada e que não gere estresse nas equipes de saúde e nos usuários que procuram o serviço de saúde".

\section{Relato de Soraya}

A entrevista com Soraya quase não ocorreu por conta da distância, ela estava morando com seus pais em Juan León Mallorquín (PY), cidade que fica a $66 \mathrm{~km}$ de Ciudad del Este (PY). Ela estava sem trabalhar no período da entrevista, porque tinha tido um bebê recentemente. Como solução para o problema da distância, a entrevista ocorreu por meio de troca de mensagens de áudio pelo aplicativo de mensagens "WhatsApp". No diálogo estabelecido com Soraya, em um determinado momento, foi questionado se ela conhecia alguma doméstica paraguaia menor de idade que trabalhasse em Foz do Iguaçu e a entrevistada deu a seguinte resposta:

Eu conheci muitas meninas menores de idade, algumas tinham 17, outras 18 e outra acima de 18, mas elas não estudavam mais, largaram o estudo para trabalhar. Tinha meninas que trabalhavam com árabes. Eu lembro que uma menina falava sempre que ela não podia comer nada, nenhuma fruta sem consentimento dos patrões. Ele fazia ela trabalhar muito, ela dormia no emprego, às vezes trabalhavam até as duas horas da manhã, depois, às cinco horas da manhã estava de novo acordada para trabalhar, porque os árabes com quem ela trabalhava faziam muitas comidas e tinha filhos. Ela falava que, cada vez que ela limpava, eles 
sujavam tudo... são coisas que eu poderia te falar que eu lembro que aconteceu. (SORAYA, fev., 2019).

O caso em análise se assemelha às situações anteriores, os patrões eram árabes e as horas de trabalho, desumanas, chegando até 21 horas consecutivas. Soraya tem formação acadêmica em Psicologia e Antropologia, trabalha como doméstica, porque ainda não conseguiu inserção em sua profıssão. Por esse motivo, um novo questionamento foi realizado: Você saberia dizer se alguma paraguaia (menor de idade) que você conheceu chegou a desenvolver algum problema psicológico ou sofreu alguma agressão desses empregadores?

Havia uma menina, ela sempre falava que, quando ia dormir, o patrão dela ia assediá-la no quarto e, quando ela falava que ia contar para sua esposa, ele falava que não podia falar, porque se não alguma coisa aconteceria com ela. E foi assim, se não era o patrão, era o filho dele, mas ela só me contou isso, depois já não fiquei mais sabendo de nada. Isso que eu estou te contando aconteceu há 10 anos já, isso quando eu comecei a trabalhar aí em Foz. Por isso estou te falando, de antes, quando eu fui trabalhar em Foz, a primeira vez que eu fui aí era um apartamento, então tinha muita gente (paraguaias) trabalhando, morando, né, e as meninas que trabalhavam tinham uma hora em que desciam e podiam se juntar para conversar um pouco. (SORAYA, fev., 2019).

Mais uma vez, acontecimentos ligados a abusos sexuais ou a tentativa de abusos sexuais são evidenciados e, ao que tudo indica, esses abusos aconteciam com frequência. Além disso, a jovem em questão era ameaçada para não contar a outras pessoas. Diante deste contexto, foi questionado se Soraya não tinha medo de trabalhar com um patrão assim ou de ser abusada.

Quando elas falavam isso, eu tinha medo, mas onde eu estava, o senhor e sua esposa eram sempre muito bons, e eu não acreditava no que elas (meninas) falavam, eu pensava, nossa! Porque comigo não foi assim, né, nunca alguém veio comigo falar essas coisas, me tratar assim, sempre as pessoas me tra- 
taram como se eu fosse da família, mas as meninas falavam que isso realmente acontecia, e eu ficava surpreendida quando elas falavam isso, porque o primeiro árabe que eu trabalhei, nossa! Era um homem muito bom, era um homem que jamais me falou de forma grosseira, nada disso, pedia as coisas com educação, nunca foi mal-educado nem nada, por isso, eu achava que as meninas, exageravam. (SORAYA, fev., 2019).

Dos 4 relatos expostos, 3 deles ligam empregadores árabes com questões referentes à exploração do trabalho, com cargas horárias de até 21 horas/dia, o que é inimaginável do ponto de vista da saúde mental, cárceres privados, tentativa de estupro e abusos sexuais.

A comunidade árabe possui uma grande representatividade em Foz do Iguaçu. E assim como brasileiros, chineses, etc. eles também contratam domésticas paraguaias. Segundo pesquisa de Baez Coronel (2017) muitas famílias árabes contratam paraguaias a partir de uma agência de emprego em Ciudad del Este, sendo que, o perfil procurado por eles são mulheres jovens, vindas da área rural e com pouca escolaridade.

Partindo do diálogo feito por Soraya e pelas considerações no parágrafo acima, pode-se inferir que a exploração, em suas várias formas, por parte de empregadores árabes em relação às domésticas paraguaias, não é regra, mas é frequente. O próprio perfil destas trabalhadoras, escolhido não por acaso, favorece a ocorrência destes tipos de exploração. São jovens sem escolaridade, vindas de áreas rurais que, ao se deslocarem para Foz do Iguaçu, se encontram como estrangeiras, sem dinheiro, sem apoio de familiares, distantes de suas casas e trabalhando dentro de uma residência fechada, de maneira quase que incomunicável.

Apesar dos relatos envolvendo famílias árabes serem os mais marcantes, situações envolvendo empregadores brasileiros também apareceram, cita-se como exemplo o caso da entrevistada que foi acusada de roubo injustamente. Mas, os relatos não envolvem apenas empregadores, em dois momentos, foi o próprio "Estado" quem causou humilhação por meio dos seus agentes públicos, ao sugerir 
que uma "carteirinha de vacina" paraguaia deveria ser jogada no lixo, por não ter valor em um posto de saúde brasileiro; ou quando negou atendimento médico a outra entrevistada por ela ser paraguaia e não ter documentos regularizados no Brasil.

\section{Considerações Finais}

A partir deste estudo, foi possível compreender um pouco da realidade vivida por um grupo de trabalhadoras paraguaias que laboram em Foz do Iguaçu no serviço doméstico. Em relação aos direitos trabaIhistas, desenhou-se um cenário problemático, sobressaindo acordos informais que pouco beneficiam essas trabalhadoras.

Com a análise das entrevistas, foi possivel perceber que é indiferente para as trabalhadoras imigrantes e para as fronteiriças possuir uma carteira de trabalho, afınal de contas, ela não será registrada. Nos diálogos estabelecidos, se questionou por qual razão elas acreditavam que os empregadores de Foz do Iguaçu as contratavam. Surpreendentemente, respostas como "as brasileiras pedem que a carteira de trabalho seja assinada, daí eles pegam as paraguaias, porque as paraguaias não terão uma carteira de trabalho para assinar" apareceram. Isso reforça a ideia de que, para elas trabalharem no Brasil, devem abdicar das proteções legais e, sem opção, elas o fazem e, por consequência, estando nesta condição, abrem espaço para toda a sorte de exploração, pois ficam desprotegidas e à mercê dos empregadores.

Foram retratados casos em que essas domésticas foram vítimas de situações de trabalho análogo a escravo, exploração infantil, abusos sexuais, tentativas de estupro, cárcere privado, humilhação, entre outros crimes, muitos deles ligados aos empregadores árabes. Esses episódios têm relação direta com a vulnerabilidade a qual se encontram essas muIheres. Por atuarem em residências através de acordos informais e pelo fato de não existir, por parte do governo, um maior controle em relação aos trabalhadores estrangeiros, elas acabam passando despercebidas aos olhos de um Estado que deveria garantir tal proteção. 


\section{Referências}

BAEZ CORONEL, Mariana Soledad. Trabajo Precarizado en la Triple Frontera: trabajadoras domesticas paraguayas en Foz do Iguaçu. (Monografia). Instituto Latinoamericano de Economia, Sociedade e Política, Universidade Federal da Integração Latino Americana, Foz do Iguaçu, 2017.

BONI, Valdete; QUARESMA, Sílvia Jurema. Aprendendo a entrevistar: como fazer entrevistas em Ciências Sociais. Em Tese., v.2, n.1, p. 68-80, jan./jul. 2005. Disponivel em: <https://periodicos.ufsc.br/index.php/emtese/article/ view/18027>. Acesso em 13 de mai. 2018.

BRASIL. Resolução $n^{\circ}$ 510, de 07 de abril de 2016. Dispõe sobre as normas aplicáveis a pesquisas em Ciências Humanas e Sociais. Diário Oficial [da] República Federativa do Brasil, Brasília, DF, 24 maio 2016. Disponível em: 〈http://conselho.saude.gov.br/resolucoes/2016/Reso510.pdf〉. Acesso em: 05 jun. 2019.

DOMÉSTICA LEGAL. Domésticas são revistadas em condomínio de Goiânia e caso gera polêmica. Rio de Janeiro, 20 de mai. de 2016. Notícias. Disponivel em: <https://www.domesticalegal.com.br/domesticas-sao-revistadas-em-condominio-de-goiania-e-caso-gera-polemica/>. Acesso em 01 de mar. De 2019.

DOMÉSTICA LECAL. Salário mínimo da empregada doméstica por estado. Rio de janeiro. Home. Disponível em: <http://www.domesticalegal.com. br/utilidades/

salario-minimo-do-empregado-domestico/>. Acesso em 15 jun. 2019.

CARDIN, Eric Gustavo; ALBUQUERQUE, José Lindomar Coelho. Fronteiras e deslocamentos. Revista Brasileira de Sociologia., v. 6, n. 12, p, 114-131, jan./ abr. 2018. Disponivel em: <http://www.sbsociologia.com.br/revista/index. php/RBS/article/view/236>. Acesso em 18 de abr. 2018

CARDIN, Eric Gustavo. A Expansão do Capital e as Dinâmicas da Fronteira. Tese (doutorado) - Programa de Pós-Graduação em Sociologia, Universidade Estadual Paulista, Faculdade de Ciências e Letras de Araraquara, 2011.

CARDIN, Eric Gustavo. Notas para o estudo dos processos migratórios no Brasil. COLOGNESE, Silvio Antônio. Fronteiras do saber sociológico. Porto Alegre: Evangraf, 2012. P. 47-64. 
FARINA, Bernado Cunha. Trabalhadores fronteiriços na tríplice fronteira: confronto entre a igualdade jurídica e a realidade. Dissertação (Mestrado) Sociedade, Cultura e Fronteira, Universidade Estadual Oeste do Paraná, Foz do Iguaçu, 2015.

IBGE CIDADES. Panorama Foz do Iguaçu. Disponível em: <https://cidades. ibge.gov.br/brasil/pr/foz-do-iguacu/panorama>. Acesso em 01 de mai. 2018.

LAKATOS, Eva Maria; MARCONI, Marina de Andrade. Técnicas de pesquisa: planejamento e execução de pesquisas, amostragens e técnicas de pesquisa, elaboração, análise e interpretação de dados. 7a. ed. São Paulo: Atlas, 2008.

LIMA, Cíntia Fiorotti; CARDIN, Eric Gustavo. Migração paraguaia na faixa de fronteira do Brasil: identidades, circularidades e redes transnacionais. Século XXI - Revista de Relações Internacionais., v. 7, p. 1-5, 2016.

LOZANO, Giovane da Silva. Mobilidade pendular transfronteiriça: uma análise dos trabalhadores paraguaios que atuam nas ruas de Foz do Iguaçu/BR. Artigo científico (Licenciatura em Ciências Sociais) - Centro de Ciências Humanas e Sociais, Universidade Estadual do Oeste do Paraná, 2017.

MACHADO, Lia Osório. Cidades na fronteira internacional: conceitos e tipologia. II Conferência Internacional Desenvolvimento Urbano em Cidades de Fronteira. Foz do Iguaçu (PR), 2006. Disponivel em: <https://www.academia. edu/27313915/2006_-_Cidades_na_fronteira_conceito_e_tipologia?auto=download>. Acesso em 01 de mar. de 2019.

PARO, Denise. Paraguaios cruzam fronteira para trabalhar ilegalmente em Foz. Gazeta do Povo, Paraná, 05 de nov. 2011. Economia, emprego. Disponível em: <https://www.gazetadopovo.com.br/economia/paraguaios-cruzam-fronteira-para-trabalhar-ilegalmente-em-foz-97m14hnjvf1cizloupi5f2q1a/>. Acesso em 25 de mai. 2016.

PARANA RPC. Paraguaias cruzam a fronteira para trabalhar ilegalmente no Brasil. G1.GLOBO. Paraná, 14 de set. 2011.Disponivel em: <http://g1.globo.com/ $\mathrm{pr} /$ parana/noticia/2011/09/paraguaias-cruzam-fronteira-para-trabalhar-ilegalmente-no-brasil.html>. Acesso em: 28 de mai. 2016.

STRADA. Cinthya de F. Oliveira. Organização dos atendimentos de saúde aos estrangeiros de um município da tríplice fronteira (Brasil, Paraguai e Argentina): Uma análise da política. Dissertação (Mestrado) - Programa de Pós-graduação em Políticas Públicas e Desenvolvimento, Universidade Federal da Integração Latino-Americano, Foz do Iguaçu, 2018. 
TRT6. Acusada de furto, doméstica ganha na Justiça direito à compensação por dano moral. Pernambuco, 26 de jun. de 2018. Notícias. Disponível em: <https://www.trt6.jus.br/portal/noticias/2018/06/26/acusada-de-furto-domestica-ganha-na-justica-direito-compensacao-por-dano-moral>. Acesso em: 13 de jun de 2019.

VINUTO, Juliana. A amostragem em Bola de Neve na pesquisa qualitativa: um debate em aberto. Temáticas., n. 44, p. 201-218, ago./dez. 2014. Disponível em: <http://www.ifch.unicamp.br/ojs/index.php/tematicas/article/download/2144/1637>. Acesso em 13 de nov. 2016.

\section{Notas}

1 Mestre em Políticas Públicas e Desenvolvimento. http://orcid.org/0000-00018035-9184. E-mail: alvesgomeseduardo@gmail.com.

2 Doutora em Ciências Sociais, professora da Universidade Federal do Rio Grande do Sul. (UFRCS) - Campus Litoral Norte, no Departamento Interdisciplinar. http:// orcid.org/0000-0002-7782-4345. E-mail: silvia.aquino@gmail.com.

3 G1.GLOBO. Paraguaias cruzam a fronteira para trabalhar ilegalmente no Brasil. Disponivel em: http://g1.globo.com/pr/parana/noticia/2011/09/paraguaias-cruzam-fronteira-para-trabalhar-ilegalmente-no-brasil.html. Acesso em: 28 de mai. 2016.

4 GAZETA DO POVO. Paraguaios cruzam fronteira para trabalhar ilegalmente em Foz. Disponível em: <https://www.gazetadopovo.com.br/economia/paraguaios-cruzam-fronteira-para-trabalhar-ilegalmente-em-foz-97m14hnjvf1cizloupi5f2q1a/>. Acesso em 25 de mai. 2016.

5 Resolução $N^{\circ}$ 510, de 07 de abril de 2016. Art. $5^{\circ} \mathrm{O}$ processo de comunicação do consentimento e do assentimento livre e esclarecido pode ser realizado por meio de sua expressão oral, escrita, língua de sinais ou de outras formas que se mostrem adequadas, devendo ser consideradas as características individuais, sociais, econômicas e culturais da pessoa ou grupo de pessoas participante da pesquisa e as abordagens metodológicas aplicadas. 